\title{
The design \& operating philosophies of panel vs block caving
}

\author{
A van As Van As Geotechnical, Australia \\ A Guest Alan Guest Technical Consulting, South Africa
}

\begin{abstract}
The modern trend of designing large underground cave mines according to their desired production throughput rather than utilizing appropriate, geotechnically driven mine design parameters, has caused considerable confusion and ultimately, culminated in poor cave performance. There is a growing tendency for caves with large footprints to be designed as panel caves regardless of their Footprint to Block height ratio. The misconception that a "panel cave" with high block height (Block height / Footprint >2) can be designed and operated no differently to that of a conventional panel cave, with smaller block height (Block height / Footprint < 2) has led to numerous geotechnical problems, including; poor cave propagation and adverse cave shape resulting in ore losses, early dilution entry, large fragmentation, ore recompaction and point loading of the extraction level, to name but a few. This paper serves to define and describe the fundamental design and operating philosophies that are characteristic of successful block and panel caves and highlights the dangers of mixing the two. It further offers an alternative for these horizontal cave layouts, namely the incline cave layout.
\end{abstract}

\section{Introduction}

It is common practice today to use 'block caving' as a generic term to describe both block and panel caves, however this erroneous use of terminology is also reflected in modern cave design. Although both block and panel caves are variants of caving mining methods, their development and production philosophies are fundamentally different.

Block caving is a mining method where the mine footprint is completely undercut prior to ramping up the draw tonnage to propagate the cave and achieve steady state production. Ideally, the footprint is equidimensional, with dimensions constrained by the grade distribution and by undercutting practicalities, such as the length of the undercut face, rate of undercut advance and requirement for uniform draw of the entire block. The height of the block is usually restricted for reasons of rock mass strength, comminution and drawpoint brow wear, but is greater than the length of the footprint. An important characteristic of a block cave is that the production draw should be relatively uniform across the footprint to control uniform cave propagation and to promote draw zone interaction that facilitates mass flow and controls dilution entry (as illustrated in Figure 1b). It is important to note that the drawpoint spacing is designed to achieve interactive draw, not only for managing dilution but also for managing column loading and preventing these vertical stresses from building up and crushing the underlying extraction level infrastructure.

A panel cave, on the other hand, is characterised by orebodies with large footprints whereby the footprint is subdivided into areas (panels) of limited dimension (where length $>$ block height) and the undercut is progressed along the length of the footprint such that the drawbell construction and commissioning rate is in equilibrium with the drawbell closure rate for the given production target. Thus, the production capacity is dictated by footprint width, column height and undercut advance rate, which for an advanced undercut is dictated by the drawbell construction rate. Another vitally important characteristic of a panel cave is that the production draw must be strictly controlled to develop and sustain an inclined ore-waste interface, as depicted in Figure $1 \mathrm{a}$ and Figure 2. 


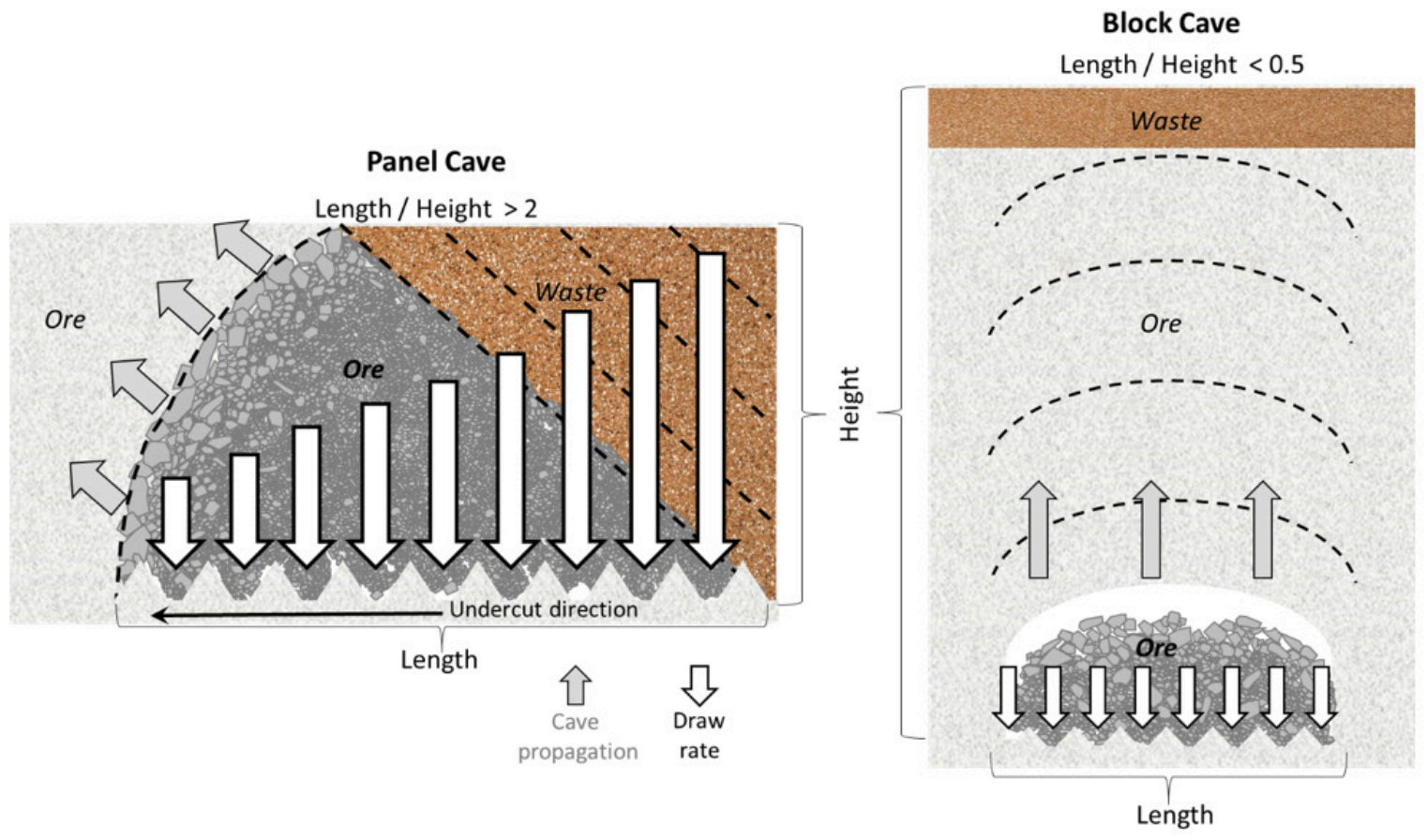

Figure 1 Panel Cave vs Block Cave, note the preferred cave-back inclination

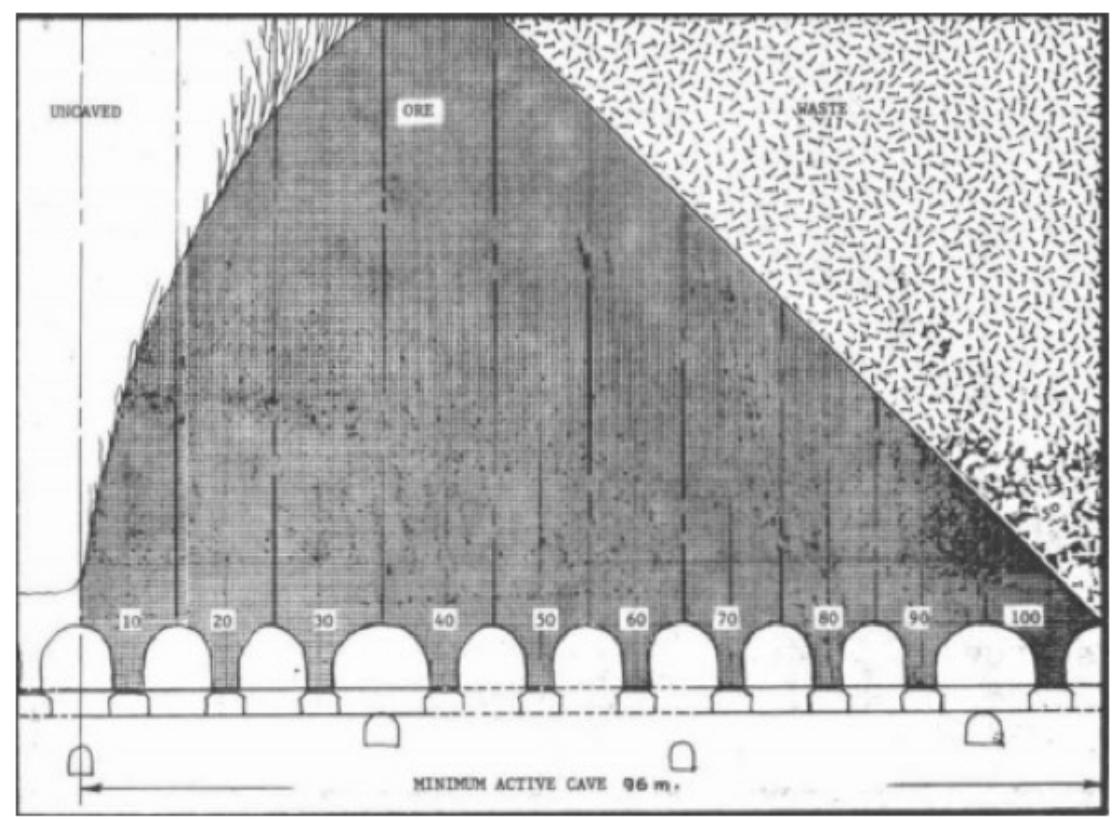

Figure 2 Typical mining sequence for a panel cave (Vera 1981)

The old Climax and Henderson mines are examples that typified panel cave mining; Vera (1981) described the 'synchronisation' of the 'mining machine' to ensure that there was "sufficient time to develop, prepare and cave enough tons to sustain the given production goal". He also stressed the importance of stringent draw control, to maintain the $45^{\circ}$ incline ore-waste interface, as a vital component to the success of the method and noted that any "wrong draw control practice will create weight, dilution, arching and migration of ore".

It is important to note that the panel caves of the past typically mined weak rock masses and therefore capped their block heights and the size of their equipment, to limit tunnel dimensions, in an effort to minimise the deleterious effects of column loading (weight) and maintain the integrity of their extraction levels. Interestingly their experience led them to space their drawpoints close together as a control to "prevent 'chimney' caving" and "avoid the formation of undrawn pillars of broken ore" (Ward 1981), rather than follow the modern trend of increasing the drawpoint spacing. 
The primary justification for the departure from these tried and tested design philosophies to higher blocks, more widely spaced drawpoints and use of mechanised equipment (i.e. changed from scrappers to LHDs) is attributed to the fact that modern mines are caving stronger orebodies with coarser fragmentation. This rationalisation seems reasonable for competent rock masses, however on closer scrutiny it is clear that the strength/stress (depth) ratios of most modern caves may be no different to the caves of old and hence will experience identical difficulties, yet arguably having less ability to manage them. One can only conclude that the drivers behind the selection of block height, drawpoint spacing, undercutting method and equipment selection are based on schedule and productivity as opposed to technical considerations.

\section{Cave design objectives}

Cave mining is almost completely reliant on natural forces and the rock mass response to those forces to be successful, which is why cave mining methods demand a thorough understanding of the geotechnical domains, their spatial distribution, their rock mass characteristics (which includes the effects of structure) as well as their response to the stress regimes induced during the various stages of caving.

Thus, the objective of cave design is to try and engineer control over the cave behaviour and performance. This is achieved by observing several experience-based rules. Ultimately, a good cave design is one where the cave can be managed safely to yield the desired production tonnage at the expected grade, with minimal dilution or ore losses over the planned life of the mine.

\subsection{Safe operation}

Caving is arguably the safest underground mining method, with the greatest hazards often occurring as a result of poor operating practices. Risks can be mitigated by adhering to sound principles that have tried and tested over decades of mining.

\subsubsection{Control undercutting rate}

Selecting manageable footprint dimensions is key to ensuring that the undercut can be advanced at a rate that will prevent the abutment stresses from overstressing the rock mass over an extended period, causing a significant reduction in the rock mass strength or an undesired seismic response.

For an advanced undercut method, the undercut advance rate is governed by the length of the undercut face and the rate of drawbell construction. Araneda \& Sougarret (2005), described the slow advance of the very wide undercut face at the Esmeralda mine that resulted in significant losses as large areas crushed under prolonged periods of high stress. The undercut advance rate for the post undercut method, is by design unconstrained by the by the drawbell opening rate and hence is comparatively less constrained by the undercut geometry (including the face length) than the advanced undercut method. However, extraction level pillars and excavations in a post undercut will suffer significant abutment stresses damage that degrades the rock mass strength and ultimately undermines the integrity of the extraction level, thus its application in deep and seismically active mines remains questionable.

\subsubsection{Control cave propagation rate \& cave back shape}

Predicting caveability is only part of the caving conundrum, the next most important question to answer is how will the cave propagate? I.e. what shapes will the cave back form during its propagation and at what rate will the cave back propagate until it breaks-through to surface or to an upper mining horizon?

The formation of an irregular cave shape is most commonly attributed to the manner in which the cave is drawn. As the rate of production draw typically controls the caving rate, it is good practice, after undercutting, to start drawing the cave slowly before 'ramping up' to steady state production draw. The reason for this gradual ramp up is to ensure that the stresses in the cave back have sufficient time to 
fracture and fail the rock mass above the cave-back and across the entire extent of the footprint, referred to as 'maturing the cave'. This 'homogenization' process should assist in promoting a more uniform response from all the geotechnical domains in the cave, i.e. enabling a similar behavioural response in respect to cave propagation - assuming that uniform draw is practiced, as illustrated by the white arrows in Figure 1 a) and b). In addition, the slow ramp up ensures that the weight of the cave column (post the attainment of critical hydraulic radius (HRcr)) will reduce the size of the early cave fragmentation.

Note that the cave propagation rate should be controlled through cave draw, if this is not observed then it is likely that the footprint is too small or the draw rate is too high and/or not uniform.

\subsubsection{Control cave muckpile}

Where the rock mass is competent and cave propagation is slow, it is imperative that the rate of draw does not exceed the caving rate or else an airgap will form. Whilst an airgap is required to allow the cave-back to fail, it is the size of that gap that is of concern here. A large airgap is a well-known hazard in cave mines as any instantaneous collapse of the cave back can force this air out onto the levels below with destructive force, or as Lett et al. (2016) describe, "force fly rock debris to eject during surface breakthrough". The only control one has in caving is through the draw at the drawpoints.

\section{$2.2 \quad$ Minimise dilution}

The successful recovery of the resource is highly dependent on minimising (usually overlying) dilution, thus most caves are designed on the assumption that:

a. the draw zones interact and thereby ensure

b. uniform draw-down (mass flow) of the caved material above the height of interaction (HIZ), as illustrated in Figure 3.

\subsubsection{Facilitate mass flow}

Mass flow occurs in the upper portion of the broken ore column where the draw zones all interact i.e. above the height of interaction (HIZ), as illustrated in Figure 3. This mass flow zone is characterised by the lack of horizontal or vertical mixing and the rates of flow of fine and coarse materials are uniform (Laubscher 2000), i.e. the material located above the HIZ all flows downwards at a uniform rate. This mass flow zone is underlain by a zone of interactive draw and intermixing in which other mechanisms of draw may operate. Thus, in order to achieve maximum recovery and minimise dilution, it is imperative that drawpoints are spaced sufficiently close to ensure interactive draw and that uniform mass flow occurs from as low as possible in the ore column. However, if individual drawpoints are drawn in isolation or drawpoints are spaced too widely for draw interaction to occur, then isolated draw predominates, as a result the height of the HIZ increases (if interaction occurs at all) and the desired pattern of uniform mass flow will be broken.

It is important to understand that the higher the interaction zone, the earlier dilution will appear at the extraction level and the more dilution will eventually be drawn to recover the planned ore. Laubscher (1994) stated that "If interactive theory is accepted then the higher the draw column the lower the dilution. This is on the basis that the ore/dilution interface will be maintained as a distinct zone and that dilution will only enter the ore column when the ore/waste contact reaches the height of the interaction zone". 


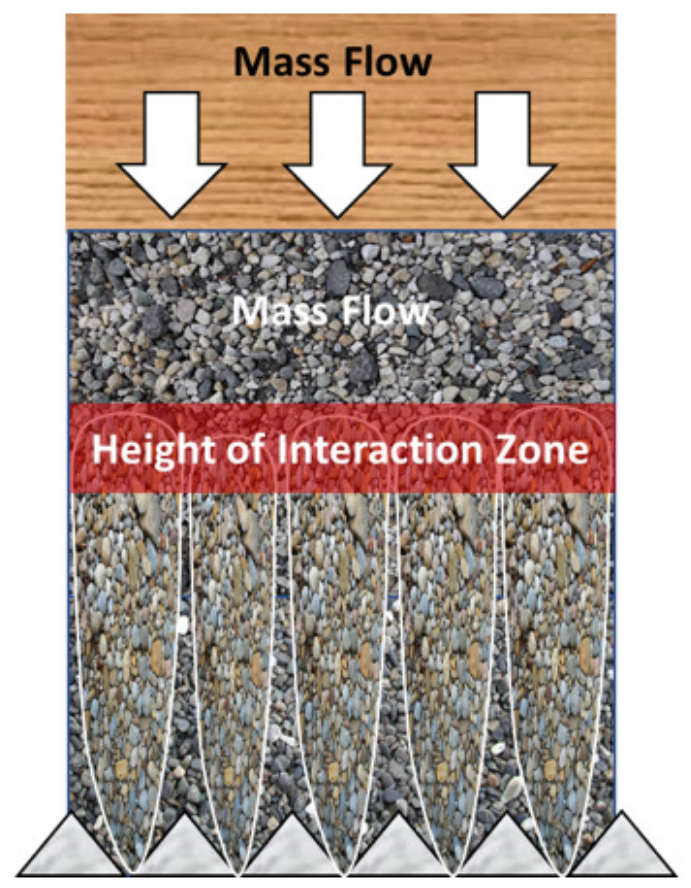

Figure 3 Illustration of Interacting draw zones leading to mass flow above the height of interaction zone (after Laubscher 1994)

\subsection{Manage column loading (weighting)}

Given that the percentage of excavation on the extraction levels is high, and that the performance of the extraction level excavations is critical to the continuity and efficiency of production, it follows that the loading (weight) of the overlying ore column will have a major influence on the extraction level design (apex pillar size and geometry) and performance (apex pillar stability). There are numerous examples of caves that have suffered the deleterious effects of vertical stress concentrations (point loading) on drawpoints and extraction drives from the stagnant, compacted (or solid) rock above.

The seemingly obvious remedy to extraction level pillar failures is to increase the drawpoint spacing to ensure that the pillars are larger and thus able to carry higher loads from the ore column above. A number of recent caves have increased the pillar size in the vertical dimension (i.e. increasing the distance between the undercut and extraction levels). Although this technique does not lower the pillar stress it may reduce the extent of the shear failure that occurs between the major apex and the extraction drive below. Anecdotal evidence appears to indicate that the rock mass conditions are improved using this technique.

However, as discussed above, drawpoint spacing is also a function of cave material flow and so increasing the pillar width serves to decrease draw zone interaction. Richardson (1981), Vera (1981), Laubscher (1981) and countless experienced caving engineers have demonstrated through models and operational experiences, that when draw zones do not interact, isolated draw develops and hence the dissipation of vertical weight through draw is unattainable. In fact, the situation is often aggravated as the vertical weight becomes concentrated in the area between isolated draw zones, i.e. point-loading. Figure 4 below illustrates the concept of stress concentration and build-up (intensity of the black lines) between two non-interacting draw zones in a 'Particle Flow Code' (PFC) model. 


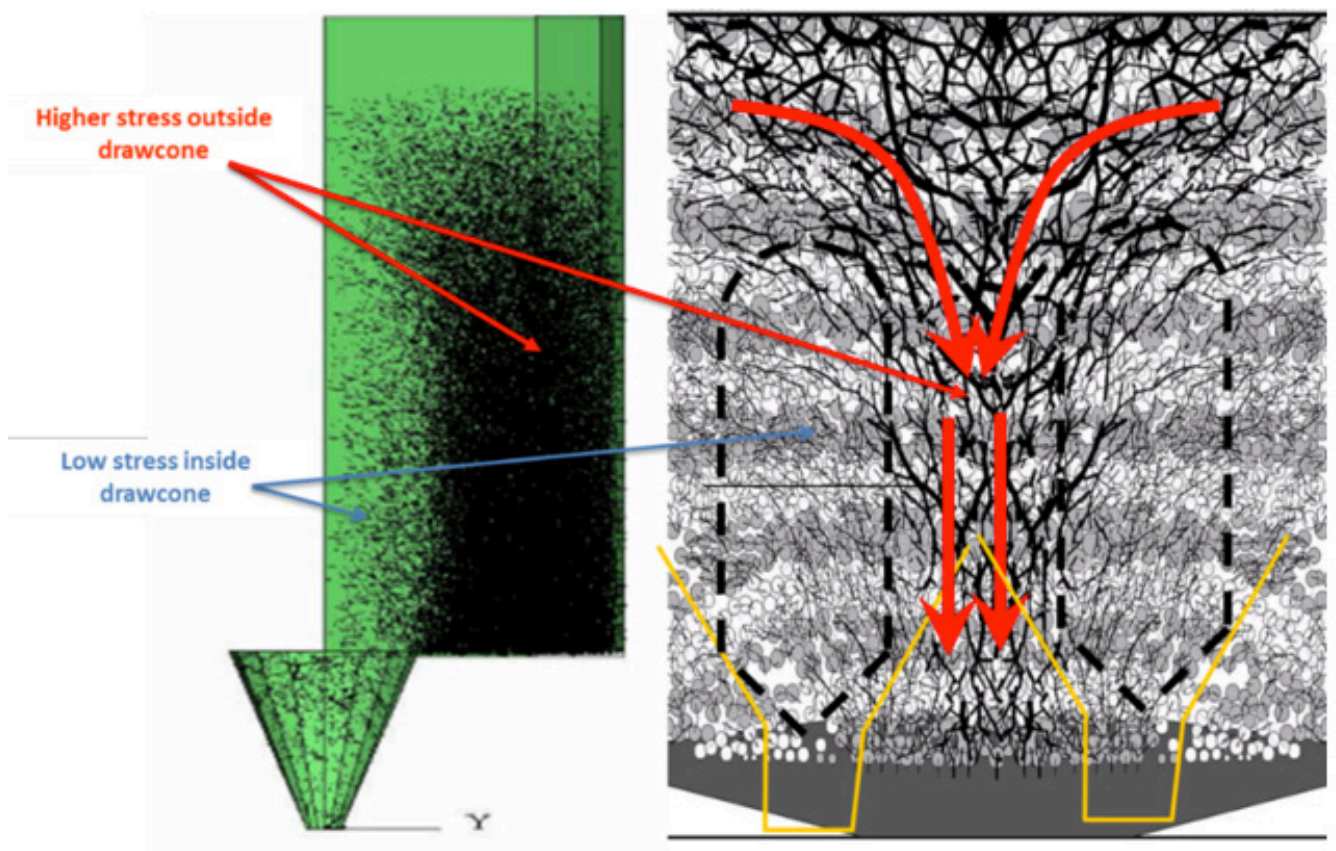

Figure 4 Illustration of the increasing stress concentration (depicted by the thickness and intensity of the black contact forces) between two non-interacting draw zones in a PFC3D Model (modified from Itasca 2005)

Thus, drawpoint spacing design must satisfy the conflicting priorities of both extraction level stability and draw zone interaction. Too closely spaced and the extraction apex pillars / drives may fail, and the integrity of the level and production is compromised. Too widely spaced and draw zone interaction may not be achieved, leading to more isolated draw and resulting in early dilution entry, higher levels of dilution and vertical stress concentrations that may lead to apex pillar/drive failures. Achieving a satisfactory, balanced solution is clearly complex and risky, however the industry trend is to blindly increase drawpoint spacing without seeking alternatives (such as reducing drive size) nor undertaking adequate investigations to justify the outcomes and quantify the downstream affects

"The lack of data on drawpoint flow allows the mining community to assume full recovery without studies to refute optimistic assumptions. Therefore, engineers are cautioned about large drawpoint spacings as the later danger of recovery loss may be catastrophic. Once mining begins, virtually no remedial action on the wide drawpoint spacing can occur and the resulting ore losses far outweigh the construction advantages." Dudley (2014).

\section{The design conundrum of high column panel caves}

"It is economically compelling to mine high columns from a single layout. There is a high capital cost to set up a layout but the cost per tonne can be reduced if a higher column can be mined." Diering (2014).

The predicament of most deep caves is that the size of the orebody needs to be fairly large in order to be profitable, given the significant capital investment and duration of preproduction development and construction. Naturally the investors would like to see timely returns on their investment and so the footprint elevation is located such that the maximum value is ensured as soon as possible.

Inevitably this translates to caves with large block heights (usually in excess of $400 \mathrm{~m}$ ) and hence the mining method lends itself to block caving. However, because the footprints are large, the cave engineers are often tempted to design a 'high column panel cave' rather than construct multiple block caves adjacent to each other (such as the Chuquicamata Macro-Block concept, described by Hormazabal et al. (2010) and Flores \& Catalan (2019). 
The problem with the high column panel cave is that it violates the principles of both block and panel caving, namely that uniform draw can never be achieved.

Why is this important?

\section{The design consequences of high column panel caves}

If mined as a large block cave, the entire undercut would need to be completed prior to ramping up the production draw, followed by even and uniform draw across the entire footprint. However, given the size of the footprint, this isn't feasible as the duration of undercutting would span years rather than months, and as a result the caved material would compact. If a 'tickle-tonne' approach was adopted to prevent compaction, then by the time the entire footprint was undercut the differential height of draw between the initial drawpoints and the last drawpoints to be commissioned would be significant and thus impossible to implement uniform draw down. Moreover, the consequence of trying to maintain a low cave draw angle is to reduce the production ramp up. This adds considerable time to the schedule prior to reaching steady state production.

However, if mined as a "high column" panel cave, then the differential draw between the depleted drawpoints and the newly constructed drawpoints would be very large and the resulting cave front angle would be very steep. This situation is further aggravated by the high draw rates demanded of high column caves with high tonnage targets and the relatively slow undercutting rates, restricted mainly by the current inability to rapidly construct drawbells.

Diering (2008), illustrated this concept well in Figure 5(a), where the state of panel cave mining at any point is represented as a diagonal line. The extraction or production rate curve (PRC) represented by the steepness of the diagonal line, i.e. a shallow PRC represents slow draw and a steep PRC represents fast draw. Note in Figure 5(b) that by increasing the height of draw (HOD) the 'Best PRC' becomes 'Slow PRC' and other lines become either too slow or too fast, i.e. the balance of drawpoint draw sequencing and good cave management becomes very difficult, often impossible.

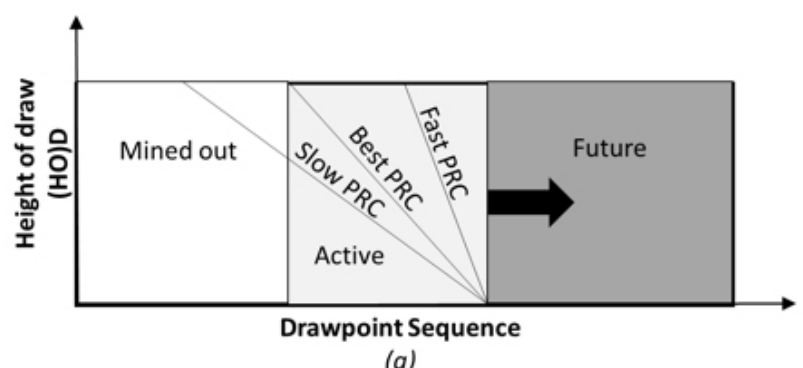

(a)

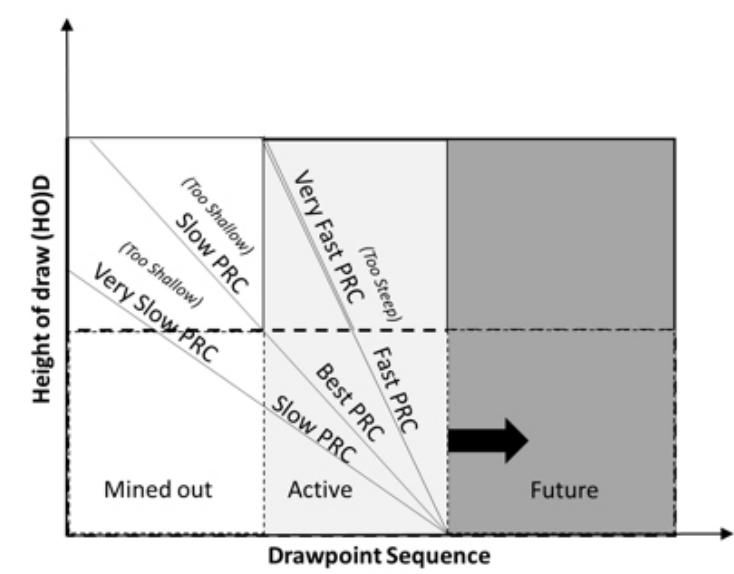

(b)

Figure 5 Representation of state of panel cave mining, with drawpoint draw sequence as a function of the HOD and production rate curve (PRC) represented by the steepness of the diagonal line. Modified from Diering (2008)

\subsection{Uncontrollable cave propagation}

The cave draw angle is not only necessary to control dilution and rocks from the upper levels rilling down the the cave muckpile of the panel, but in the case of a high column panel, the irregular cave shape formed will modify the stresses in the cave-back such as the lagging cave front could become destressed and not encounter the same high stresses experienced at the leading cave back area, as illustrated in Figure 6. 
Thus, the steep cave front, associated with a high column panel cave is likely to result in:

- sporadic, uncontrolled caving,

- potential cave stall,

- irregular cave-back shape,

- loss of ore in uncaved wedges of ore forming along the lagging cave boundary.

- Higher incidents of major seismic events (rockbursts)

- Early cave breakthrough, often observed as chimneying / ratholing

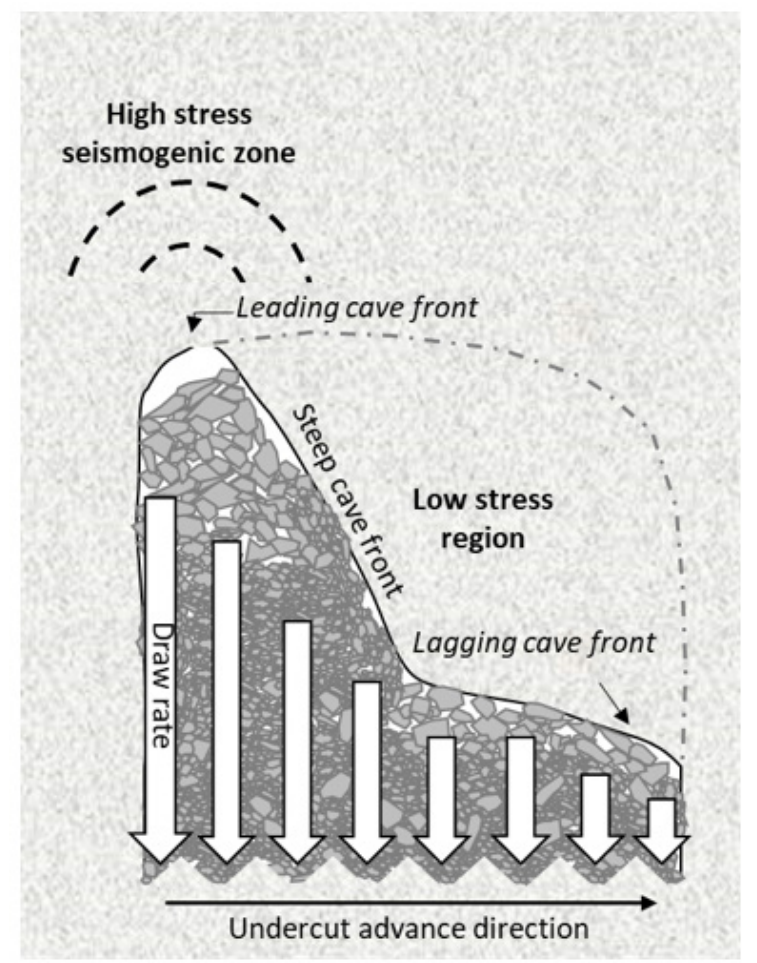

Figure 6. High column panel cave - irregular cave back shape with steep cave front which facilitates rilling and rapid material movement. Draw control on the right has no effect on the cave propagation on the left

It has been argued that weak major geological structures are directly responsible for accelerated, localised caving; however scrutiny of the draw data at several mines has demonstrated that isolated draw in conjunction with high draw rates serves to accelerate localised cave propagation, often manifest as chimney caving and ratholing on surface; as opposed to slow uniform draw which affords greater control.

Simply put, controlling the cave propagation rate and cave back shape through draw control becomes unmanageable when the cave draw angle is very steep, as illustrated in Figure 6. Furthermore, monitoring such a cave back profile by near vertical drillholes is extremely difficult.

\subsection{Isolated draw and uncontrolled flow}

"High column" panel caves do not lend themselves to good cave management, particularly if they are deep and designed to yield large tonnages. As described in section 2.2 and 2.3, in an effort to strengthen the extraction level layout, drawpoint spacings are typically spaced too widely apart for draw zone interaction to occur. The conflicting tensions between apex pillar strength and interactive draw is a difficult balance to achieve and most engineers opt for the near-term extraction level integrity over long term orebody integrity. As a result, isolated, non-interactive draw, is rarely achieved and this is manifest as: 
- early dilution,

- sustained dilution, and

- the inability to shed column loading through draw control (i.e. convergence and crushing of excavations on the extraction level).

\subsubsection{Early dilution and sustained dilution}

Isolated, non-interactive draw facilitates the rapid movement of caved material within the draw zone and thus any overlying dilution (which is common to most cave mines), rapidly migrates into the drawpoint and dilutes the grade of the extracted material. In caves where interactive draw prevails and draw control is practiced, it is not uncommon for overlying dilution entry to be observed after more than $60 \%$ of the column has been drawn. However, where isolated draw occurs, it is not uncommon for dilution entry to be recorded after $30 \%$ column draw, with some mines even observing ratholing to surface followed by dilution entry after only $10 \%$.

\subsubsection{Draw rates and dilution}

Experience has demonstrated that high draw rates are known to further promote isolated draw, whilst slow uniform draw promotes interaction and reduces dilution, as described by Susaeta (2004). Based on their observations, Susaeta et al. (2008), demonstrated the direct relationship between dilution and uniform draw and suggested the use of a 'Uniformity Index'. Susaeta et al. (2008), goes on to conclude that,

"the overall trend for a dilution perspective is to reinforce the use of close spaced layout draw points. This result goes against the industry trend of using widely spaced

layout in order to achieve higher productivity and more reliable rock mechanic design".

There is a common misconception that if the fragmentation is fine enough to be easily loaded then there is no longer any requirement to adhere to ramp up rules. However, the reason behind adhering to ramp up rules is to facilitate the 'cave maturity' process, causing the 'homogenisation' of the rock mass in the cave back and not simply to induce smaller primary fragmentation and minimise oversize, although this is certainly a benefit.

It is the author's opinion that rapid ramp up and high draw rates are the primary cause of the cave propagation problems, including an increase in seismic activity and incidence of rockbursts, as listed in section 4.1. A case in point is the Northparkes, E26 Lift 2 cave where Ross (2008) describes the cave ramp up:

"The original plan had assumed that production would ramp up as draw points were progressively opened across the level. In fact, all the draw points were blasted before the ground handling system was completed, which meant that the entire block was ready for production as soon as the system was commissioned. This allowed a rapid build-up and planned peak production levels were reached in less than 12 months from production start-up (August 2004). Production exceeded planned capacity in October 2005, with 500,000t being produced during the month. This equates to an annualised rate of $6 \mathrm{Mt}$, which exceeds the planned capacity of 5.2Mt. This rate was maintained in 2006 and so both the extraction level design and ground handling system can be considered to be effective." Ross (2008).

Interestingly Hudyma et al. (2008a), described a direct correlation between the production draw rate and the seismic response and rapid cave propagation, all of which resulted in a substantial amount of ore loss due to incomplete caving. 


\subsubsection{Column loading on the extraction level}

The mechanisms for point loading of the extraction level excavations by the concentrated weight of high vertical columns, is described in section 2.3. What is important for the design engineer to understand is that the only mitigation tool at their disposal, to relieve point loading, is to draw the area in an attempt to 'shed the load' elsewhere. However, if the draw zones do not interact or take a considerable amount of draw and time before they finally interact, then the shedding of point loads is not possible through draw and the excavations will require frequent rehabilitation or eventually converge to closure.

It is interesting to note that some mining companies now consider drawpoint losses as inevitable and include estimates of drawpoint loss and associated reserve loss in their cave reserve estimation process.

\section{$5 \quad$ The solution to high column panel caves}

The problems associated with high column panel caves have been appreciated by many in the industry and hence many mines still observe the practice of capping the block heights to ensure cave management. Others have explored various caving variants and/or practices as described below.

\subsection{Macro blocks}

During the past decade, there has been several planned caves which have been designed to produce in excess of 50,000 tonnes per day. This in turn has led to very large footprints required to achieve this tonnage. It is not uncommon during the development of a cave to have problems, which lead to delays in achieving the tonnage build-up. Having the option of two smaller caves, which are able to produce the desired tonnage, provides flexibility to the operation in the event of problems being experienced in any one particular cave.

\subsection{Manageable sized block caves}

Designing smaller caves, which can be undercut within a reasonable period, enabling the cave to achieve steady state draw is far more effective that attempting to build a cave of twice the size, which requires twice as long to undercut before steady state draw is achievable.

\subsubsection{Complete undercut before production ramp up}

Once undercutting commences, it is imperative that the undercut progresses steadily across the footprint. During early undercutting it is possible to briefly stop and start the undercut in an effort to sort out minor technical problems being experienced e.g. the undercut ring blast pattern and timing. However, once the undercut dimension nears 50 percent of the critical hydraulic radius, the undercutting process must be a smooth-running operation.

This therefore dictates that the ground handling systems must be up and running well in advance of the undercutting process. If this is not the case, ground cannot be removed from the drawpoints, which means that the cave-back will not have sufficient void to propagate upwards.

\subsubsection{Uniform draw}

By inference, the back of a block cave should be drawn down in a horizontal, uniform manner. However, as the start-up of a block cave requires the undercut to progress in a similar manner to that of a panel cave, the initially undercut drawpoints need to be drawn at a very reduced rate until the cave has been completely undercut. This often leads to problems, either from reduced draw not been adhered to, or too little being drawn, and excessive loading noted on the extraction horizon. Excessive draw can eventually lead to the initial sector being drawn too hard before the end of the undercut has been achieved, invariably resulting in early dilution entry. Having the back of the cave at a very steep angle across the cave-back also leads to ground rilling down the top of the cave-back / muckpile which inhibits the growth of the cave on the lower side, as demonstrated in Figure 6. 


\subsection{Inclined cave}

One of the problems that cave mines come to experience as they progress deeper is that the strength of the rock mass generally does not change but the increasing depth leads to much higher stresses. One of the biggest problems to overcome during the design of a horizontal block cave, is dealing with the high abutment stress generated by the undercutting phase.

This problem can be overcome to some extent by utilising an Incline cave layout, as depicted in Figure 7 (a).

Inclined caving is variant of block caving where the drawpoints are distributed across multiple levels, very similar to that of a Transverse Sublevel cave layout, in that the drives are developed across the shorter axis of the orebody. These drives are then retreated, blasting rings again in a very similar manner to that of the Sublevel cave.

On the upper most (overcut) level, the blasting will continue across the entire orebody, above where drawpoints will be established later. On subsequent lower levels the blasting will stop short of the level above in a predetermined manner to create the Incline cave layout as illustrated in Figure 7(b). The spacing between drives on the horizontal as well as the stopping distance on the tunnel below will be determined by the predicted fragmentation, similar to that used for the design of a conventional horizontal block cave layout.

When the layout is observed in plan view, the various drawpoints that have been established will have a very similar layout to that of a Horizontal Block cave.
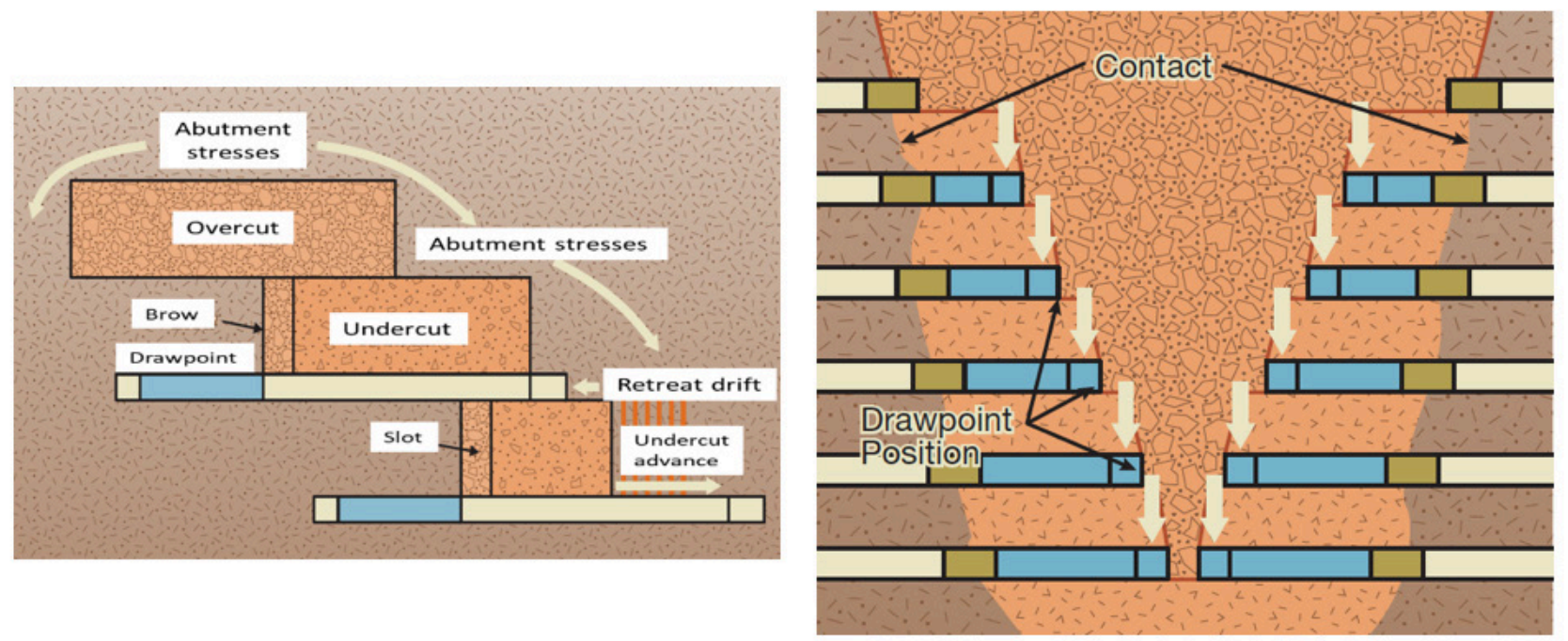

Figure 7 (a) The arrangement to reduce the effect of abutment stress during undercutting. (b) A section through a Double-sided Incline Cave after Laubscher et al. 2017

The mining method has typically been used for inclined orebodies, such as past asbestos mines in Zimbabwe, as illustrated in Figure 8. 


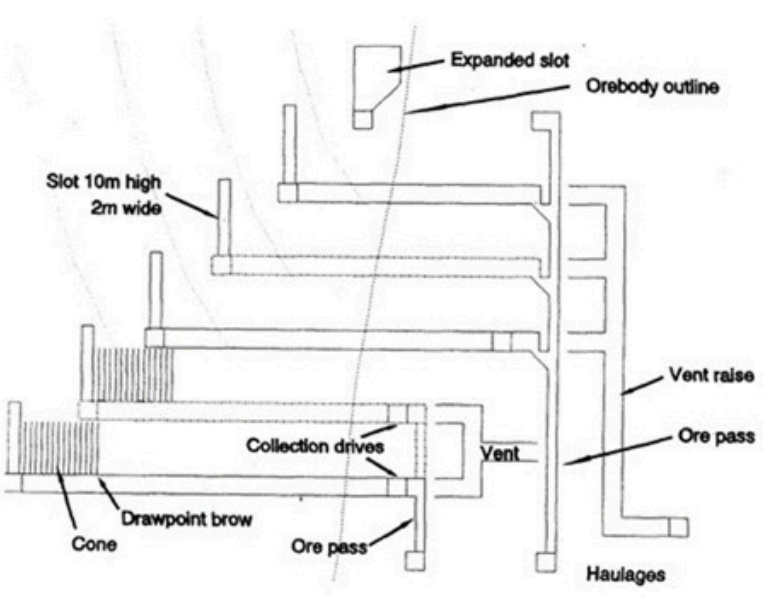

(a) (a)

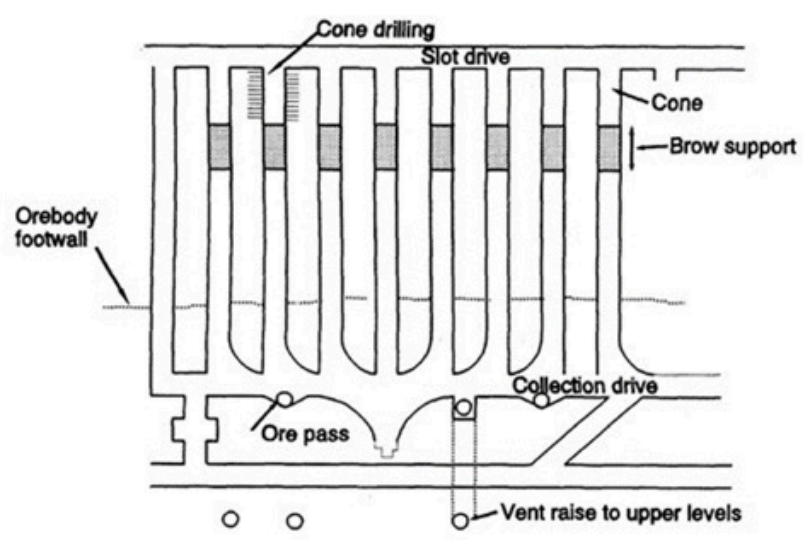

(b)

Figure 8 Inclined drawpoint caving, King Mine, Zimbabwe, (a) vertical section showing extraction level layout, and (b) plan showing sublevel layout (Laubscher \& Esterhuizen 1994)

There are numerous advantages to the Incline cave beside that of reducing the problems associated with the undercut. Brow wear can be managed by moving the brow back in the Drawpoint Drive, but if this becomes excessive, a new level can be developed at the base of the cave, and the sectional profile reestablished. Also, as the material becomes finer and interactive draw begins to deteriorate, the drawpoint spacing can be altered to decrease the effective inter-drawpoint spacing, allowing for interactive draw to continue.

Thus, an inclined cave may prove a ready solution to solving the current problems inherently associated with conventional block and panel caves at depth, particularly around layout stability, draw interaction and associated stress management and dilution control.

\section{Conclusions}

The design of deep, high block, large footprint caves as panel caves rather than block caves has resulted in numerous operational difficulties that are difficult/impossible to manage. Typical geotechnical issues that can be attributed to high column panel caves include:

- sporadic, uncontrolled caving,

- potential cave stall,

- irregular cave-back shape,

- loss of ore in uncaved wedges of ore forming along the lagging cave boundary,

- Early cave breakthrough, often observed as chimneying / ratholing,

- early dilution,

- sustained dilution, and

- the inability to shed column loading through draw control (i.e. convergence and crushing of excavations on the extraction level).

To effectively combat these issues, cave design considerations (whether using the advanced or post undercutting method) must avoid forming steep cave fronts and develop layouts that look beyond a simple trade-off between increasing drawpoint spacings and draw interaction. Instead, the tension between opposing design constraints could be resolved through the adoption of variant cave mining methods that could satisfy the well-established, tried and tested cave design criteria and yet still ensure cave propagation control, infrastructure stability and dilution management. 


\section{References}

Araneda, O \& Sougarret, A 2008, 'Lessons learned in cave Mining: El Teniente 1997-2007', in H Schunnesson \& E Nordlund (eds), Proceedings of MassMin 2008, 9-11 June, Lulea, Sweden. pp. 43-52.

Diering, T 2014, 'Reserve Estimation for Block Cave Mines Using PCBC.', Mineral Resource and Ore Reserve Estimation - The AUSIMM Guide to good practice. Second edition, Monograph 3. AusIMM, Carlton, Victoria, pp. 542-555.

Diering, T 2008, 'Block cave scheduling with a piece of paper', in H Schunnesson \& E Nordlund (eds), Proceedings of MassMin 2008, 9-11 June, Lulea, Sweden, pp. 303-508.

Dudley, JA 2014, 'Block Caving Software - Practical Applications', Mineral Resource and Ore Reserve Estimation - The AUSIMM Guide to good practice, Second edition, Monograph 3. AusIMM, Carlton, Victoria, pp. 535-546.

Flores, G \& Catalan, A 2019, 'A transition from a large open pit into a novel "macroblock variant" block caving geometry at Chuquicamata mine, Codelco Chile', Journal of Rock Mechanics and Geotechnical Engineering, vol.11, no. 3, June 2019, pp. 549-561.

Flores, G E 2005, 'Rock mass response to the transition from open pit to underground cave mining', PhD thesis (unpublished), University of Queensland, Brisbane.

Hormazabal, E, Villegas, F, Rovira, F \& Carranza-Torres, C 2010, 'Geomechanical evaluation of macro-block caving options using 3D numerical modelling at Chuquicamata underground project in Chile', in Y Potvin (ed.), Proceedings of the Second International Symposium on Block and Sublevel Caving, Australian Centre for Geomechanics, Perth, pp. 469482.

Hudyma,M, Allison, D \& Potvin, E, 2008a, 'Seismic monitoring of the Northparkes Lift 2 block cave - Part 1 production caving', Journal- South African Institute of Mining and Metallurgy, vol. 108, no. 7, pp. 421-430.

Hudyma,M, Allison, D \& Potvin, E, 2008b, 'Seismic monitoring of the Northparkes Lift 2 block cave - Part 1 production caving', Journal- South African Institute of Mining and Metallurgy, vol. 108, no. 7, pp.421-430.

Laubscher, DH, Guest, AR \& Jakubec, J 2017, 'Guidelines on Caving Mining Methods; The Underlying Concepts'. JK Publications, The University of Queensland, Australia.

Laubscher, DH, 2000, 'Block Caving Manual', International Caving Study. JKMRC and Itasca Consulting Group, Inc, Brisbane.

Laubscher, DH, 1994, 'Cave mining - the state of the art', Journal of the South African Institute of Mining Metallurgy, 94(10), Johannesburg, pp. 279-293.

Laubscher, DH \& Esterhuizen, GS, 1994, 'Inclined drawpoint caving - a cave-mining method'. Proceedings XVth Commonwealth Mining and Metallurgical Institutions Congress, South African Institute of Mining and Metallurgy and Geological Society of South Africa: Johannesburg, pp. 247-250.

Laubscher, DH, 1981, 'Selection of underground mass mining methods', D R Stewart (ed.), Design and Operation of Caving and Sublevel Stoping Mines, Society of Mining Engineers, AIME: New York, pp. 23-38.

Lett, JL, Brunton, I, Capes, GW, Jäger, A, Mobilio, B, Rachocki, J, Sharrock, GB \& Secheny, M 2016, 'Undercutting to surface breakthrough - Cadia East Panel Cave (Stage 1)', in C Carr \& G Chitombo (eds), Proceedings of MassMin 2016, Melbourne, Australia, pp. 65-82.

Richardson, MP 1981, 'Area of draw influence and drawpoint spacing for block caving mines', D R Stewart (ed.), Design and Operation of Caving and Sublevel Stoping Mines, Society of Mining Engineers, AlME: New York, pp 149-156.

Ross, I 2008, 'Northparkes E26 Lift 2 block cave - A case study', in H Schunnesson \& E Nordlund (eds), Proceedings of MassMin 2008, 9-11 June, Lulea, Sweden, pp. 25-34.

Susaeta, A, Rubio, E, Henríquez, J \& País, G 2008, 'Dilution behaviour at Codelco panel cave mines', in C Carr \& G Chitombo (eds), Proceedings of MassMin 2016, 9-11 June, Lulea, Sweden, Lulea, Sweden, pp. $167-178$.

Susaeta, A, 2004, 'Theory of gravity flow (Part 1)', in A Karzulovic \& M.Alfaro (eds), Proceedings of MassMin 2004, Santiago, pp. 167-172. 
Vera, SG 1981, 'Caving at Climax. Chapter 14', D R Stewart (ed.), Design and Operation of Caving and Sublevel Stoping Mines, Society of Mining Engineers, AIME: New York, pp 157-176.

Ward, MH 1981, 'Technical and economical considerations of the block caving mine', D R Stewart (ed.), Design and Operation of Caving and Sublevel Stoping Mines, Society of Mining Engineers, AIME: New York. 